\title{
Relationship of Teacher Resources to Cognitive Abilities of Philippine- and US- Based Filipino Mathematics Teachers
}

\author{
Author: Virginia R. Arceo, Ph.D. ${ }^{1}$; Ma. Nympha B. Joaquin, \\ Ph.D. ${ }^{2}$ \\ Affiliation: Assistant Professor, College of Science, University of Santo Tomas ${ }^{1}$; Professor, \\ College of Education, University of the Philippines ${ }^{2}$ \\ E-mail:vvrarceo@ust.edu.ph ${ }^{1}$; mbjoaquin@up.edu.ph ${ }^{2}$
}

DOI: 10.26821/IJSRC.9.2.2021.9206

\begin{abstract}
The paper aimed to identify significant relationship between teacher resources and their cognitive abilities as well as significant differences in cognitive abilities of two groups of Filipino mathematics teachers: General Mathematics STEM teachers from the Philippines, and high school mathematics teachers from the United States of America. Cognitive abilities included Mathematics Content Knowledge (MCK) and Mathematics Pedagogical Content Knowledge (MPCK) with two domains, content and cognitive, while teacher resources include teaching materials, classroom management, work load, and use of technology. Analyses of primary data were conducted using non-parametric tests such as Mann-Whitney U Test and Spearman-rank Correlation. Results indicated that for MCK, no significant differences for content domain was found while a significant difference on reasoning of the cognitive domain between the two groups of teachers emerged. In terms of MPCK, there were also no significant differences in both content and cognitive domains. Teacher resources like the use of technology has significant positive correlation to cognitive abilities. The number of teaching materials has significant positive correlation to MPCK while teaching assignment has significant negative correlation to MCK.
\end{abstract}

Keywords: Teacher resources, mathematics content knowledge, mathematics pedagogical content knowledge.

\section{INTRODUCTION}

The Philippines implemented the $\mathrm{K}$ to 12 curriculum that added two more years to the basic education in order to align with the global educational standards. This resulted in the implementation of senior high school grades eleven and twelve, which started in 2016. Emphasis on Science, Technology, Engineering, Mathematics (STEM) was done in order to produce more Filipino scientists. And with this change in curriculum, questions arise as to the availability of teaching resources and readiness of teachers' cognitive abilities in order to support the demand of the curriculum. In order to address these matters, other organizations (as the government and private institutions like the STEM Leadership Alliance) conducted teacher trainings (Rongco, 2019). Given the precedence of benchmarking set by the STEM Leadership Alliance, this study chose Filipino mathematics teachers in the United States as comparison to mathematics teachers in the Philippines.

This study focused on high school mathematics teacher competence, specifically the General Mathematics teachers from the STEM strand. The mathematics teacher competence was measured by their cognitive abilities such as mathematics content knowledge (MCK) and mathematics pedagogical content knowledge (MPCK). Exploring these teacher characteristics between the two groups of Filipino mathematics teachers could help in the identification of significant differences in teacher knowledge and practices. Moreover, relationship of teacher resources such as teaching materials, classroom management, work load, and use of technology to cognitive abilities is further analyzed in this study. 
Volume 9 Issue 2 February 2021

\section{TEACHER RESOURCES}

Cohen, Raudenbush, and Ball (2003) identified several educational resources that might help achieve high-quality instruction. It comprised resources available within teachers' environment, including guidance for instruction and collaboration. It also included teachers' knowledge of subject matter, learners, and materials appropriate for supporting learning and teachers' skill in motivating learners to apply themselves to classroom tasks (Cohen et al., 2003). Other factors may also affect teacher competence, characteristics, performance or instruction such as seminars attended (Abarro, 2018), curricular materials (Beyer, Delgado, Davis, \& Krajcik, 2009), management factors and working environment (Hasbay \& Altindag, 2018), building and facilities, elements relating to students, and compensation policy (Nguyen et al., 2016). The various resources of teaching either ease or toughen the workload of teachers.

A local study made by Abarro (2018) in search of factors affecting the performance of public school teachers working in the Division of Antipolo City. Using a survey research design, he found that among his education-related variables, highest educational attainment of teachers and scholastic rating has significant association to teacher classroom performance. In addition, work-related variable like the local seminars attended by the teachers also had a significant association to teacher classroom performance. This was in agreement with the study of Essien, Akpan \& Obot (2016) that there is a positive relationship between the frequency of teachers' attendance to training, seminars and workshops to their classroom performance.

Curricular materials like books, manipulatives, calculators, and other forms of technology were also part of teacher resources. Kafyulilo, Fisser, \& Voogt (2015) investigated the factors that lead to the continuous use of technology of teachers from Tanzania inside the classroom. According to them, the encouragement and support of school management were critical factors in teachers' continuation of technology use. However, problems like large class size, unstable electricity supply, lack of time and lack of technology tools, affected the teachers continuous use of technology in their classrooms. Hence, the need to stabilize institutional factors and consistent support of school management is necessary in teachers' continuation of technology use.

Institutional resources such as curriculum materials, colleagues and grade-level peers, class size, access to professional development, and professional growth opportunities were explored by Hill, Blazar, \& Lynch (2015) along with teacher background characteristics and teacher knowledge, beliefs and dispositions as predictors of instructional quality. The aim of their study was to provide guidance on how resources might be allocated to improve teachers' classroom behavior, which may result to improved student outcomes. However, their findings were not able to account differences on instructional resources due to varying school district situations. One district experienced intensive professional development as well as teacher coaching for at least ten years already while other districts only reached small subset of teachers in their professional development programs. This implies unequal teacher opportunities that calls for budget allocation to the corresponding school districts.

Ultimately, addressing the need of various teacher resources would enrich the instructional practice and the teachers' competence. This may be in the form of numerous reference books, availability of technology, support of school officials, and additional professional development programs.

\section{COGNITIVE ABILITIES}

Cognitive abilities include Mathematics Content Knowledge (MCK) and Mathematics Pedagogical Content Knowledge (MPCK) from the Teacher Education Development Study in Mathematics (TEDS-M) (2008). MCK refers to the "mathematics that teachers know and can do" (Krainer et al., 2015, p. 103) while MPCK refers to "knowledge about how to assist students to learn mathematics" (Krainer et al., 2015, p. 103).

The fundamental idea of teacher content knowledge according to Shulman (1986) is the extent of knowledge in their mind and how it was organized. Moreover, Shulman also stated that teachers should not only understand what something was all about but also why was it acceptable and correct. Campbell et al. (2014) claimed that MCK was comprised of knowledge of mathematical facts and procedures and knowledge of mathematical concepts and generalizations. In the framework of Philippine mathematics education, MCK was regarded as the primary responsibility of mathematics teachers because they were expected to know and understand very well not just the content they were assigned to teach but mathematics content of the next grade or year levels (SEI-DOST \& MATHTED, 2011).

As an attempt to measure MCK, Ekawati, Lin \& Yang (2014), found that many primary teachers in Indonesia lacked a conceptual understanding of the mathematics they were teaching. They developed an MCK test specific to ratio and proportion. Factor analysis was used to identify three factors of MCK, these were meaning of proportional and non-proportional situations, number structures in situation, and figural representation. Cluster analysis was then used to analyze groups of teachers who answered the test items similarly. 
Volume 9 Issue 2 February 2021

They found out that teachers performed worse on figural representation but were able to perform better on computations through the application of their knowledge in number structures in situation. Overall, Indonesian primary teachers were found to be lacking mathematics content knowledge with the goal of improving it through pre-service programs.

Moreover, in MPCK, Hauk, Toney, Jackson, Nair, \& Tsay (2014) mentioned that PCK was more than an overlap of knowledge. It was about how teacher understanding helps thinking and knowledge building about content and students, teaching implementations, and of the curriculum. In short, PCK was a notion that characterizes the knowledge teachers use in their course of teaching (Kind, 2009). Or as Krepf et al. (2018) puts it, PCK referred to the context-specific knowledge that teachers activate when reflecting on practice.

In a recent study, Ozdemir, Sahin, Basibuyuk, Erdem, \& Soylu (2017) examined the PCK of classroom teachers in Turkey in terms of their Knowledge of instructional strategies and Knowledge of understanding students. They conducted an 8-item adapted MPCK test where results were analyzed using one-way ANOVA and correlation analysis. The results showed that there was no significant difference for both PCK components between the groups of teachers, preservice and in-service. Furthermore, a significant relationship between the teachers knowledge of instructional strategies and knowledge of understanding students existed. This simply implied that the teachers in the study had underdeveloped and insufficient pedagogical content knowledge.

\section{STATEMENT OF THE PROBLEM}

This study aims to compare and identify relationships between the characteristics of two groups of Filipino mathematics teachers: those in the Philippines and those in the United States of America.

Specifically, this study sought to answer the following questions:

1. How do Filipino mathematics teachers in the Philippines and in the United States of America differ in terms of cognitive abilities, specifically in the following domains of mathematics content knowledge (MCK):

a. Content domain; and

b. Cognitive domain?

2. How do the two groups of Filipino mathematics teachers differ in terms of cognitive abilities, specifically, in the following sub-dimensions of mathematics pedagogical content knowledge (MPCK):
a. Mathematical
curricular

b. Knowledge of planning for
mathematics teaching and
learning; and
c. Enacting mathematics?

3. Is there a significant relationship between teacher resources and their cognitive abilities?

\section{METHODOLOGY}

Quantitative research design was used to analyze and interpret the results of the researcher developed tests gathered from both groups of mathematics teachers. Non-parametric tests were used to identify the presence of significant differences and relationships in teacher resources, MCK, and MPCK.

The 64 Philippine respondents were Grade 11 General Mathematics STEM teachers from various public and private schools from the National Capital Region. While the 23 US-based high school mathematics teachers were from public schools only from various states such as California, Nevada, Texas, Arizona, South Carolina, Maryland, and New York. All respondents were given a questionnaire composed of: (1) respondent's profile; (2) a 15-item multiple choice researcher-made MCK Test that covered content domains such as Functions and Graphs, Business Mathematics, and Logic, and cognitive domains namely, Knowing, Applying, and Reasoning; (3) a 9-item open constructed response researcher-made MPCK Test that covered the same content domains as the MCK Test, and cognitive domain such as mathematical curricular knowledge, knowledge of planning, and enacting mathematics.

\section{RESULTS AND DISCUSSION}

The two groups of Filipino mathematics teachers are compared in terms of their MCK, MPCK, and resources. The results of the MCK test analyzed per content domain is shown in Table 1. There were no significant differences per content domain between the two groups of mathematics teachers. The result of the Mann-Whitney $U$ test for Functions was insignificant, $\mathrm{U}=577.0, \mathrm{z}=-1.57, \mathrm{p}$ $=.1160$. The mean rank for group $\mathrm{PH}$ was 41.52 and the mean rank for group US was 50.91. This suggests that the distribution of scores on functions for $\mathrm{PH}$ group was not significantly different from the distribution of scores for the US group. A similar case can be observed in Business Math, $\mathrm{U}=$ 672.5, $\mathrm{z}=-0.70, \mathrm{p}=.4837$, and Logic $\mathrm{U}=674.0, \mathrm{z}$ $=-0.64, \mathrm{p}=.5237$. Strength in Functions was evident because of familiarity with the lessons and teaching experience in both groups. However, both groups of teachers did not show full confidence in teaching Business Math and Logic for one reason or another. 
Volume 9 Issue 2 February 2021

\begin{tabular}{llllll}
\hline Table 1. Mann-Whitney Test for MCK Content \\
Domain by Location \\
\cline { 1 - 2 } $\begin{array}{l}\text { Content } \\
\text { Domain }\end{array}$ & Mean Rank & & & \\
\cline { 2 - 3 } & PH & US & $U$ & $z$ & $p$ \\
\hline Functions & 41.52 & 50.91 & 577.0 & -1.57 & 0.1160 \\
Business & & & & & \\
Math & 43.01 & 46.76 & 672.5 & -0.70 & 0.4837 \\
Logic & 43.03 & 46.70 & 674.0 & -0.64 & 0.5237 \\
\hline$* p<.05$ & & & & &
\end{tabular}

modeling, and solving routine problems), have no significant differences. This implies that the basic content knowledge in terms of knowing and applying are carried by Filipino teachers wherever they go. However, there is a significant difference in reasoning between the two groups. This can be attributed to clearer standards in the United States where reasoning and sense making are expected to occur in every mathematics classroom every day (NCTM, 2013).

For MPCK test, which were also grouped

Past researches covered a narrow range of mathematics content domain. Topics on arithmetic, algebra, estimate, place value, fractions, ratio and proportion, and geometry (An, 2009; Ekawati, Lin, \& Yang, 2014; Faulkner \& Cain, 2013; Hill, Schilling, \& Ball, 2004; Krauss et al., 2008; Norton, 2018; Olfos, Goldrine, \& Estrella, 2014; Şahin \& Soylu, 2017; Shahbari, 2017; Venkat \& Spaull, 2015) have been the concentration of numerous studies. The addition of Business Mathematics and Logic to the growing body of content domains in MCK is timely with the recent change in the Philippine curriculum. However, no significant differences were found between the two groups of Filipino mathematics teachers.

\begin{tabular}{|c|c|c|c|c|c|}
\hline \multirow{2}{*}{$\begin{array}{l}\text { Content } \\
\text { Domain }\end{array}$} & \multicolumn{2}{|c|}{ Mean Rank } & \multirow[b]{2}{*}{$U$} & \multirow[b]{2}{*}{$z$} & \multirow[b]{2}{*}{$p$} \\
\hline & $\mathrm{PH}$ & US & & & \\
\hline $\begin{array}{l}\text { Functions } \\
\text { Business }\end{array}$ & 44.37 & 42.98 & 712.5 & & \\
\hline Math & 43.20 & 46.24 & 684.5 & & \\
\hline Logic & 44.50 & 42.61 & 704.0 & -0.32 & 0.7454 \\
\hline
\end{tabular}

Moreover, the items in the MCK test were also divided according to cognitive domain: Knowing, Applying, and Reasoning. Table 2 shows that there is a significant difference in Reasoning between the two groups of mathematics teachers, $\mathrm{U}=524.5, \mathrm{z}=$ $-2.18, p=.0294$. The mean rank for group PH was 40.70 and the mean rank for group US was 53.20. This suggested that the distribution of scores on Reasoning for PH group was significantly different from the distribution of scores for the US group. On the other hand, there was no significant difference in Knowing, $U=696.5, z=-0.40, p=$ .6868 , and Applying, $\mathrm{U}=646.5, \mathrm{z}=-0.90, \mathrm{p}=$ .3691 between the two groups.

\section{Table 2. Mann-Whitney Test for MCK $* p<.05$ Cognitive Domain by Location}

In particular, what the two groups of Filipino mathematics teachers know (which includes recall, recognition, computation, and classification), and what they can apply (which includes selecting the appropriate operation or method, representation, according to content and cognitive domains, are open constructed response type and each of the nine questions weigh two points, where a respondent can get one point for partially correct answers. Test results show that more than half of the respondents got less than $50 \%$ score on Functions and Business Math. There was only one Philippine-based mathematics teacher who got a perfect score for Business Math while none from America were able to perfect the section. Moreover, the results in Logic shows that only $12.5 \%$ of the Philippine-based mathematics teachers scored at least $50 \%$ compared to $8.6 \%$ of the US-based mathematics teachers. These figures imply that most Philippine-based mathematics teachers have difficulty or unfamiliarity with the topics covered in Business Math and Logic. The US-based mathematics teachers also showed insufficient knowledge in both content domains which could be attributed to the non-inclusion of those lessons in their curricula.

\section{Table 3. Mann-Whitney Test for MPCK Content Domain by Location} $* p<.05$

Table 3 shows that there are no significant differences per content domain between the two groups of mathematics teachers. The result of the Mann-Whitney $\mathrm{U}$ test for Functions was insignificant, $\mathrm{U}=712.5, \mathrm{z}=-0.23, \mathrm{p}=.8184$. The mean rank for group PH was 44.37 and the mean

\begin{tabular}{lccccc}
\hline \multirow{2}{*}{$\begin{array}{l}\text { Cognitive } \\
\text { Domain }\end{array}$} & \multicolumn{2}{c}{ Mean Rank } & & & \\
\cline { 2 - 3 } KH & US & $U$ & $z$ & $p$ \\
\hline Knowing & 43.38 & 45.72 & 696.5 & -0.40 & 0.6868 \\
Applying & 42.60 & 47.89 & 646.5 & -0.90 & 0.3691 \\
Reasoning & 40.70 & 53.20 & 524.5 & -2.18 & $0.0294^{*}$
\end{tabular}
rank for group US was 42.98. Although the mean rank for PH group was higher, the results suggested that the distribution of scores on functions for the said group was not significantly different from the distribution of scores for the US group. Similar case can be observed in the other two content domains. There were no significant differences on the Business Math scores, $\mathrm{U}=684.5, \mathrm{z}=-0.51, \mathrm{p}=$ 
Volume 9 Issue 2 February 2021

.6127 , and Logic scores $\mathrm{U}=704.0, \mathrm{z}=-0.32, \mathrm{p}=$ .7454 , between the two groups of teachers.

Similar to content domain, no significant differences were also observed in the test scores per cognitive domain. Table 4 shows the result of the Mann-Whitney $U$ test for Curricular Knowledge $(\mathrm{U}=647.5, \mathrm{z}=-0.88, \mathrm{p}=.3772)$, Knowledge of Planning $(\mathrm{U}=660.5, \mathrm{z}=-0.74, \mathrm{p}=$ $.4614)$, and Enacting Knowledge $(\mathrm{U}=732.5, \mathrm{z}=$ $0.03, p=.9723$ ) are all insignificant between the two groups of teachers. Thus, even if the mean rank of one group was higher than the other, the distribution of scores of one group was not significantly different from the distribution of scores for the other group.

Table 4. Mann-Whitney Test for MPCK Cognitive Domain by Location $* p<.05$

The study of Ozdemir et al. (2017) also examined PCK between classroom teachers in Turkey with similar sub dimensions as the cognitive domain. They found that there were no significant differences on the PCK between the groups of teachers and they had underdeveloped and insufficient pedagogical content knowledge. This result was similar to the MPCK Tests quantitative findings. No significant differences were found between the Philippine and US-based mathematics teachers and they have low MPCK scores. This implies that their MPCK may also be insufficient, thus, needing professional development activities that will enhance and widen their pedagogical content knowledge.

For teacher resources and its relationship to MCK and MPCK, factors such as the use of technology, availability of teaching materials, classroom management, teaching assignment and need of professional development came about. These factors somehow affected to teacher knowledge and performance. Table 5 shows the correlation between the teacher resources to cognitive abilities.

Table 5. Spearman Correlation Analysis between the resources to cognitive abilities

\begin{tabular}{lll}
\hline Teacher Resources & MCK & MPCK \\
\hline Technology & $.37^{* *}$ & $.24^{*}$ \\
Teaching Materials & 0.21 & $.21^{*}$ \\
Teaching Assignment & $-0.23^{*}$ & 0.02 \\
$\begin{array}{l}\text { Number of Professional } \\
\text { Development }\end{array}$ & 0.20 & 0.11 \\
\hline
\end{tabular}

A significant positive correlation was observed between Use of Technology and MCK ( $\mathrm{rs}=0.37$, p $<.001$ ) and MPCK ( $\mathrm{rs}=0.24, \mathrm{p}=.024)$. The correlation coefficients of each cognitive abilities to use of technology indicates moderate and small effect size, respectively. Table 6 supports the result

\begin{tabular}{llllccc}
\hline \multirow{2}{*}{$\begin{array}{l}\text { Cognitive } \\
\text { Domain }\end{array}$} & \multicolumn{2}{c}{ Mean Rank } & & & \\
\cline { 2 - 3 } & PH & US & & $z$ & $p$ \\
\hline $\begin{array}{l}\text { Curricular } \\
\text { Knowledge }\end{array}$ & 45.38 & 40.15 & 647.5 & -0.88 & 0.3772 \\
$\begin{array}{l}\text { Knowledge } \\
\text { of } \\
\text { Planning }\end{array}$ & 42.82 & 47.28 & 660.5 & -0.74 & 0.4614 \\
$\begin{array}{l}\text { Enacting } \\
\text { Knowledge }\end{array}$ & 43.95 & 44.15 & 732.5 & -0.03 & 0.9723 \\
\hline
\end{tabular}

of the correlation. The use of technology added to teacher knowledge particularly to their strategy in teaching. Both groups of teachers use PowerPoint presentations more than the traditional classroom technology (chalkboard or whiteboard). The big difference between the two groups was the use of interactive computer programs. Only $43.75 \%$ of the Philippine-based mathematics teacher respondents used interactive computer programs as compared to $86.96 \%$ of the US-based respondents. Additionally, $39.13 \%$ of the latter utilized other forms of technology such as Smart Board, and ELMO projector. The programs and other technologies used by US-based respondents were provided by their schools or districts. They were exposed to various teaching materials that they could easily access and use in class. Unlike the situation of the Philippine-based teachers, whose resources are limited because of school poor allocation. This situation of the Philippine-based respondents was similar to the findings of Kafyulilo, Fisser, \& Voogt (2016). According to them, time was listed as the biggest setback to the use of technology in teaching as well as lack of technological tools in schools (Kafyulilo et al., 2016). Thus, opportunities to use technology through proper time allotment in planning the curriculum should be observed. There should also be professional development programs were the teachers would be trained to use appropriate technologies that is accessible in their classrooms. As Kafyulilo et al. emphasized, a professional development program that enable teachers to develop knowledge and skills of integrating technology in teaching without access to technological tools will not lead to the integration of technology in teaching.

Table 6. Profile of the Respondents on the Use of Technology $(\mathrm{PH}=64, \mathrm{US}=23)$

\begin{tabular}{|c|c|c|c|c|}
\hline \multirow[b]{2}{*}{ Technology } & \multicolumn{2}{|c|}{ PH } & \multicolumn{2}{|c|}{ US } \\
\hline & $\mathrm{f}$ & $\%$ & f & $\%$ \\
\hline $\begin{array}{l}\text { Chalkboard/Whit } \\
\text { eboard }\end{array}$ & 45 & $70.31 \%$ & 18 & $78.26 \%$ \\
\hline $\begin{array}{l}\text { PowerPoint } \\
\text { Presentation }\end{array}$ & 59 & $92.19 \%$ & 20 & $86.96 \%$ \\
\hline $\begin{array}{l}\text { Interactive Comp } \\
\text { Programs }\end{array}$ & 28 & $43.75 \%$ & 20 & $86.96 \%$ \\
\hline Calculator & 52 & $81.25 \%$ & 20 & $86.96 \%$ \\
\hline
\end{tabular}


Volume 9 Issue 2 February 2021

\begin{tabular}{lllll}
\hline Others & 6 & $9.38 \%$ & 9 & $39.13 \%$ \\
\hline
\end{tabular}

Aside from use of technology, the accessibility of other teaching materials also contributed to teacher characteristics. A significant positive correlation was observed between MPCK and Teaching Materials $(\mathrm{rs}=0.21, \mathrm{p}=.049)$. The correlation coefficient between them was 0.21 , indicating a small effect size. Cognitive abilities, specifically MPCK, through availability of reference books and other teaching materials may be enhanced. The teachers' pedagogical content knowledge develops while using curricular materials especially when they need to move out of their comfort zone and have to apply new teaching style (Beyer, Delgado, Davis, \& Krajcik, 2009). This poses a conflict in the situation of Philippine-based teachers because some teachers have only one reference book made available to them when they would first teach General Mathematics. Unlike in the United States, when there will be a new preparation, new books will be given accompanied by proper training. The readiness of teaching materials somehow contributed to the confidence of the teacher and the abundance of curricular materials added to their pedagogical content knowledge. A list of other teaching materials is shown in Table 7.

Table 7. Teaching Materials Provided by the

\begin{tabular}{llcll}
\multicolumn{4}{c}{ School (PH = 64, US = 23) } \\
\hline $\begin{array}{llcc}\text { Teaching } \\
\text { Materials }\end{array}$ & $\mathrm{f}$ & $\%$ & $\mathrm{f}$ & $\%$ \\
\hline $\begin{array}{l}\text { Overhead } \\
\text { Projector }\end{array}$ & 21 & $32.81 \%$ & 13 & $56.52 \%$ \\
$\begin{array}{l}\text { Computer } \\
\text { and LCD }\end{array}$ & 46 & $71.88 \%$ & 23 & $100.0 \%$ \\
$\begin{array}{l}\text { Proj. } \\
\text { Calculator }\end{array}$ & 31 & $48.44 \%$ & 21 & $91.30 \%$ \\
Others & 14 & $21.88 \%$ & 13 & $56.52 \%$ \\
\hline
\end{tabular}

Table 7 reveals that the US-based respondents had a higher accessibility to other forms of teaching materials such as overhead projector, computer and LCD projector, calculator, and others. More than half of the US-based respondents (56.25\%) checked that their school provided other teaching materials, similar to that of technology, which included Smart Board, clickers, and ELMO projector. While only $21.88 \%$ of the Philippinebased respondents mentioned that there were other teaching materials provided by the school that were not on the list. These were television, laptop, and iPad. Hence, supply of additional curricular materials for the Philippine-based mathematics teachers is necessary and would be helpful in their everyday instruction, as well as to the advancement of the status of Philippine classrooms.
Finally, a significant negative correlation was observed between Teaching Assignment and MCK ( $\mathrm{rs}=-0.23, \mathrm{p}=.033)$. The correlation coefficient between the two indicates a small effect size. Multiple workload or teaching assignment posed a problem on teacher productivity and decreased content knowledge. Table 8 summarizes the respondents teaching load in a semester. It can be observed that some of the Philippine-based mathematics teachers have heavier workload than their US counterparts specifically those who have three or more preparations. The mastery and quality of instruction is threatened by the situation our teachers are in. Hence, assigning a manageable workload is recommended in order to increase teacher knowledge.

Table 8. Teaching assignment of the respondents

\begin{tabular}{lll}
\hline \multicolumn{3}{c}{ Philippine-based respondents } \\
\hline Gen Math only & $f$ & $\%$ \\
Gen Math and another math & 26 & 40.6 \\
Gen Math and non-math & 8 & 39.1 \\
More than 3 preps & 5 & 7.8 \\
$N$ & 64 & 100.0 \\
\hline$\quad$ US-based respondents & \\
\hline One Math subject only & $f$ & $\%$ \\
Two different math subj & 2 & 8.7 \\
Math and non-math & 18 & 78.3 \\
More than 3 preps & 3 & 13.0 \\
$N$ & 0 & 0.0 \\
\hline
\end{tabular}

\section{CONCLUSION}

Cognitive abilities included MCK and MPCK wherein both have two domains, content and cognitive domains. The content domain was based on the general lessons covered on the Department of Education Grade 11 General Mathematics curriculum which included functions and graphs, business mathematics, and logic. No significant differences per content domain, for both MCK and MPCK, between the two groups of mathematics teachers. This tells us that the level of content and pedagogical content knowledge of Filipino mathematics teachers was not dictated by their teaching location. However, MPCK needs more improvement especially on content domains like Business Mathematics and Logic. For cognitive domain on MCK namely, knowing, applying, and reasoning, the US counterparts have significantly higher reasoning than the Philippine-based respondents while no significant differences were observed when paired with MPCK. 
Volume 9 Issue 2 February 2021

Teaching resources that includes teaching materials, classroom management, work load, and use of technology also contributed to the mathematics teachers' cognitive abilities. Specifically, the use of technology has significant positive correlation to cognitive abilities. The number of teaching materials has significant positive correlation to MPCK. Teaching assignment has significant negative correlation to MCK.

\section{REFERENCES}

[1]. Rongco, C. (2019). Industry, education leaders to strengthen STEM education in $\mathrm{PH}$ for future innovators and Industry 4.0-ready workforce.

[2]. Cohen, D. K., Raudenbush, S. W., \& Ball, D. L. (2003). Resources, instruction, and research. Educational Evaluation and Policy Analysis, 25(2), 119-142. doi:10.3102/01623737025002119

[3]. Abarro, J.O. (2018). Factors Affecting the Performance of Public School Teachers in the Division of Antipolo City, Philippines. International Research Journal of Engineering and Technology (IRJET), 5(11), 1284-1290.

[4]. Beyer, C., Delgado, C., Davis, E. A., \& Krajcik, J. (2009). Investigating teacher learning supports in high school biology curricular programs to inform the design of educative curriculum materials. Journal of Research in Science Teaching, 46, 977-998. doi: 10.1002/tea.20293

[5]. Hasbay, D., \& Altindag E. (2018). Factors That Affect the Performance of Teachers Working in Secondary-Level Education. Academy of Educational Leadership Journal, 22(1), 1-19.

[6]. Nguyen T. N., Nguyen T. N. L., \& Nguyen T. P. T. (2016). Factors Affecting Secondary and High School Teachers' Professional Competence in Ethnic Minority Areas - A Case of Tay Nguyen, Vietnam. International Journal of Education and Research, 4(11), 151-164.

[7]. Essien, E.E., Akpan, O.E. \& Obot, I.M. (2016). The Influence of In-service Training, Seminar and Workshop Attendance of Social Studies Teachers on Academic Performance of Students in Junior Secondary Schools In Cross River State, Nigeria. Journal of Education and Practice, 7(22), 31-35.

[8]. Kafyulilo, A., Fisser, P. \& Voogt, J. (2016). Factors affecting teachers' continuation of technology use in teaching. Educ Inf Technol, 21, 1535-1554. doi: 10.1007/s10639-0159398-0

[9]. Hill, H.C., Blazar, D., Lynch K. (2015). Resources for Teaching: Examining Personal and Institutional Predictors of High-Quality
Instruction. AERA Open, 1(4), 1-23. doi: 10.1177/2332858415617703

[10]. Krainer, R., Hsieh, F. J., Peck, R., \& Tatto, M. T. (2015). The TEDS-M: Important Issues, Results and Questions. The Proceedings of the 12th International Congress on Mathematical Education. doi: 10.1007/978-3-319-12688-3_10

[11]. Shulman, L. S. (1986). Those who understand: Knowledge growth in teaching. Educational Researcher, 15(2), 4-14.

[12]. Campbell, P.F., Nishio, M., Smith, T.M., Clark, L.M., Conant, D.L., Rust, A.H., DePiper, J., N., Frank, T.J., Griffin, M.J., \& Choi, Y. (2014). The Relationship Between Teachers' Mathematical Content and Pedagogical Knowledge, Teachers' Perceptions, and Student Achievement. Journal for Research in Mathematics Education, 45(4), 419-459.

[13]. SEI-DOST \& MATHTED, (2011). Framework for Philippine Mathematics Teacher Education. Manila: SEI-DOST \& MATHTED.

[14]. Ekawati, R., Lin, F.L., Yang, K.L. (2014). Developing an instrument for measuring teachers' mathematics content knowledge on ratio and proportion: a case of Indonesian primary teachers. International Journal of Science and Mathematics Education. doi: 10.1007/s10763-014-9532-2

[15]. Hauk, S., Toney, A., Jackson, B., Nair, R., \& Tsay, J.J. (2014). Developing a Model of Pedagogical Content Knowledge for Secondary and Post-Secondary Mathematics Instruction. Dialogic Pedagogy: An International Online Journal, 2, 16-40. doi: 10.5195/dpj.2014.40

[16]. Kind, V. (2009). Pedagogical content knowledge in science education: perspectives and potential for progress. Studies in Science Education, 45(2), 169-204.

[17]. Krepf, M., Plöger, W., Scholl, D., \& Seifert, A. (2018). Pedagogical Content Knowledge of Experts and Novices-What Knowledge Do They Activate When Analyzing Science Lessons? Journal of Research in Science Teaching, 55(1), 44-67. doi: 10.1002/tea.21410

[18]. Ozdemir, B., Sahin, O., Basibuyuk, K., Erdem, E., \& Soylu, Y. (2017). Development of pedagogical content knowledge of classroom teachers on the numbers in terms of two components. International Journal of Research in Education and Science (IJRES), 3(2), 409-423. doi:10.21890/ijres.327899

[19]. An, S. (2009). Chinese Teachers' Knowledge of Teaching Multi-digit Division. 
Volume 9 Issue 2 February 2021

Journal of Mathematics Education, 2(1), 2754.

[20]. Faulkner, V.N. \& Cain, C.R. (2013). Improving the Mathematical Content Knowledge of General and Special Educators: Evaluating a Professional Development Module That Focuses on Number Sense. Teacher Education and Special Education, 36(2), 115-131. doi: 10.1177/0888406413479613

[21]. Hill, H.C., Schilling, S.G., \& Ball, D.L. (2004). Developing Measures of Teachers' Mathematics Knowledge for Teaching. The Elementary School Journal, 105(1), 11-30.

[22]. Krauss, S., Brunner, M., Kunter, M. \& Baumert J. (2008). Pedagogical Content Knowledge and Content Knowledge of Secondary Mathematics Teachers. Journal of Educational Psychology, 100(3), 716-725. doi: 10.1037/0022-0663.100.3.716

[23]. Norton, S. (2018). The relationship between mathematical content knowledge and mathematical pedagogical content knowledge of prospective primary teachers. J Math Teacher Educ. doi 10.1007/s10857-018-9401$\mathrm{y}$

[24]. Olfos, R., Goldrine, T., \& Estrella, S. (2014). Teachers' pedagogical content knowledge and its relation with students' understanding. Revista Brasileira de Educação, 19(59), 913-944.

[25]. Sahin, O., \& Soylu, Y. (2017). The development of content knowledge of prospective middle school mathematics teachers on Algebra. European Journal of Education Studies, 3(8), 181-213. doi: 10.5281 /zenodo. 825312

[26]. Shahbari, J.A. (2017). Mathematical and Pedagogical Knowledge amongst First- and Second-Grade In-service and Pre-service Mathematics Teachers. International Journal for Mathematics Teaching and Learning, 18(1), 41-65.

[27]. Venkat, H., \& Spaull, N. (2015). What do we know about primary teachers' mathematical content knowledge in South Africa? An analysis of SACMEQ 2007. International Journal of Educational Development, 41, 121-130. doi: 10.1016/j.ijedudev.2015.02.002

[28]. National Council of Teachers of Mathematics for the Council of the Accreditation of Educator Preparation. (2012). NCTM CAEP Standards - Secondary (Initial Preparation). 